\title{
Validation of Methods for Determination of Metabolic Rate in the Edholm Scale and ISO 8996
}

\section{Lina Giedraityte}

Department of Human Work Sciences, Luleå University of Technology, Sweden

\section{Ingvar Holmér \\ Désirée Gavhed}

\section{Department of Occupational Health, National Institute for Working Life, Stockholm, Sweden}

The aim of this study was to validate the Edholm scale (Edholm, 1966) and the ISO 8996 standard (International Organization for Standardization [ISO], 1990) by comparing the metabolic rates estimated for both methods with the actual measured metabolic rate $\left(\mathrm{M}_{\text {Meas }}\right)$ in 6 manual material handling tasks simulated under laboratory conditions. The metabolic rate was calculated from oxygen consumption $\dot{\mathrm{VO}}_{2}$ (19 participants) according to Standard No. ISO 8996 (ISO, 1990). Additionally, the participants estimated perceived exertion using the Borg scale. The metabolic rates derived from the Edholm scale $\left(\mathrm{M}_{\text {Edh }}\right)$ overestimated 5 of 6 activities by $34-50 \%(\alpha=.05)$. The metabolic rates derived from ISO $8996\left(\mathrm{M}_{\mathrm{ISO}}\right)$ overestimated all activities by $7-38 \%(\alpha=.05)$.

energy expenditure heat production light and moderate work manual tasks heart rate RPE

We wish to thank Kalev Kuklane for his editorial suggestions concerning this manuscript, Eva Karlsson for her assistance, and the participants for their co-operation.

Correspondence and requests for reprints should be sent to Désirée Gavhed, National Institute for Working Life, Department of Occupational Health, S-112 79 Stockholm, Sweden. E-mail: <desiree@niwl.se>. 


\section{INTRODUCTION}

In many ergonomic studies, the evaluation of worker's energy expenditure is required. Knowledge of the metabolic rate is required, for example, in the assessment of working practices, energy cost of specific jobs or sport activities, and the total energy cost of an activity (Standard No. ISO 8996; International Organization for Standardization [ISO], 1990). Determination of metabolic rate becomes a crucial task in the investigation of the thermal working environment as the metabolic rate (and thus the endogenous heat production) is a determinant variable for thermal comfort and thermal strain (Horwat, Meyer, \& Malchaire, 1988).

The direct measurement of oxygen consumption provides the most accurate estimate of metabolic heat production (Standard No. ISO 8996, ISO, 1990). However, it is difficult to measure oxygen uptake in the field, as measuring equipment is usually expensive, and sometimes it is impossible to measure oxygen consumption due to working conditions (e.g., during mast work). Furthermore, measurements significantly interfere with work performance, which leads to biased results (Horwat et al., 1988). The direct measurement of oxygen consumption in the field has to be limited to selected working periods (because of discomfort it can hardly be extended beyond $30 \mathrm{~min}$ ), which are then considered as representative of the whole task. This work sampling procedure may be a source of error in work load evaluation over the whole working shift (Malchaire, Wallemacq, Rogowsky, $\&$ Vanderputten, 1984). These limitations make other, simpler, metabolic rate evaluation methods more practical for field measurements.

Other methods to assess heat production are direct and indirect calorimetry methods (these require a rather large number of different measurements) and simpler indirect methods based on heart-rate measurements (Nielsen \& Meyer, 1987), pulmonary ventilation (Datta \& Ramanathan, 1969; Ford \& Hellerstein, 1959), cardiac output (Muzi et al., 1985), surface electromyography of the main muscles (Bobet \& Norman, 1982), or acceleration measurement (Montoye et al., 1983). Most of these methods present drawbacks as far as equipment and work interference are concerned, or are likely to be appropriate only for specific types of activities (Horwat et al., 1988). The most common of the indirect methods are observations of physical activities (Edholm, 1966; Standard No. ISO 8996, ISO, 1990) or estimations of perceived exertion by the worker himself (Borg, 1970).

One observational method proposed by Horwat et al. (1988) divides the work done into elementary tasks, postural activity and displacement, taking 
into consideration their sequence and duration. By using tables such as those proposed by Standard No. ISO 8996 (ISO, 1990), the metabolic rate of each of these elementary activities can be determined and the energy expenditure of the whole period estimated by summing the energy costs of elementary activities over the period of time. The Edholm scale (Edholm, 1966) assesses metabolic rate based on the recordings of occupational activities and the duration of those activities (Kähkönen et al., 1992).

Ilmarinen, Knauth, Klimmer, and Rutenfranz (1979) reported that the metabolic rates were overestimated for occupational activities in six branches of industry with no heavy physical work that belongs to the categories "Sitting or standing with very light movements or activities" and "Activities with low intensity" of the Edholm classification (Edholm, 1966) system. The metabolic rates of the "producing information" groups that are classified in the same categories tended to be overestimated as well.

Methods based on the observation of worker's activities do not interfere with the work procedure, but require well-trained observers. A study by Kähkönen et al. (1992) revealed that the metabolic rate derived from the Edholm scale (Edholm, 1966) was higher than that from the Standard No. ISO 7243 (ISO, 1989) tables with differences between individual observers of tens of $\mathrm{W} / \mathrm{m}^{2}$ and in some cases over $100 \mathrm{~W} / \mathrm{m}^{2}$. Furthermore, the differences in the estimations of metabolic rate between the observers were sometimes up to $60 \%$.

The study by Ilmarinen et al. (1979) validated the Edholm scale (Edholm, 1966) under field conditions. This study aimed to validate the Edholm scale (Edholm, 1966) and the Standard No. ISO 8996 (ISO, 1990) tables under laboratory conditions. It was designed to compare the measured metabolic rate under laboratory conditions during different manual tasks with the metabolic rate estimated by two methods: the Edholm scale (Edholm, 1966) and Standard No. ISO 8996 (ISO, 1990).

\section{METHODS}

\subsection{Participants}

Nineteen (14 males, 5 females) healthy participants volunteered to take part in the experiment. Before the experiment, the participants were informed of the details of the experimental procedures and the associated risks and discomforts. The participants' mean age was 29.0, SD 5.4 years, average 
body mass $69.2 \mathrm{~kg}, S D 12.7 \mathrm{~kg}$, average height $1.72 \mathrm{~m}, S D 0.09 \mathrm{~m}$ and average estimated body surface (DuBois area) $1.81 \mathrm{~m}^{2}, S D 0.17 \mathrm{~m}^{2}$. The participants were asked to abstain from strenuous physical activity on the morning of the measurement in order to minimise residual effects on the metabolic rate measurements.

\subsection{Measurements}

The study was limited to involve activities of low $\left(65<\mathrm{M} \leq 130 \mathrm{~W} / \mathrm{m}^{2}\right)$ and moderate $\left(130<\mathrm{M} \leq 200 \mathrm{~W} / \mathrm{m}^{2}\right)$ metabolic rate (Standard No. ISO 8996, ISO, 1990). Six manual material handling tasks occurring in normal work were designed under laboratory conditions (Table 1). A metabolic rate value $\left(\mathrm{M}_{\mathrm{Edh}}\right)$ for each of the activities was derived from the Edholm scale (Edholm, 1966). Metabolic rates $\mathrm{M}_{\mathrm{ISO}}$ were derived from the Standard No. ISO 8996 (ISO, 1990) tables. The participants performed the tasks in a random sequence. As the metabolic rate shows diurnal fluctuations, the measurements were always conducted in the morning (8.30-13.00) under thermoneutral conditions (ambient temperature 22.1-22.4 ${ }^{\circ} \mathrm{C}$ ).

Oxygen consumption $\left(\dot{\mathrm{VO}}_{2}\right)$ was measured with a MetaMax ${ }^{\circledR}$ Metabolic Testsystem (Cortex Biophysik $\mathrm{GmbH}$, Germany). It consisted of a base unit (gas analyses), a moistening Nafion ${ }^{\circledR}$ tube (to guarantee constant humidity during the measurement), a facemask with a head cap assembly together with a Triple-V® volume transducer. Fahlgren, Wiktorin, and Bernmark (1997) reported that oxygen consumption measurements conducted with MetaMax ${ }^{\circledR}$ were reliable and that the measured values agreed with values measured with the Douglas bag technique. The correlation coefficient between values measured with MetaMax ${ }^{\circledR}$ and the Douglas bag was .99 .

Participants were accustomed to the apparatus before measurements were made. The morning resting metabolic rate $\left(\mathrm{M}_{\text {Rest }}\right)$ at normal room temperature was measured to obtain a reference point in the study before measuring metabolic rates when participants were performing various tasks. Participants took their latest meal at least $2 \mathrm{hrs}$ before the experiment began, and were at rest (lying for at least $10 \mathrm{~min}$ ) while measuring $\mathbf{M}_{\text {Rest }}$. Oxygen consumption $\left(\mathrm{V}_{2}\right)$ was measured every $10 \mathrm{~s}$ continuously during the whole time of the experiment without participants taking off the facemask. Every time a participant exhaled the pump in the base unit started working in proportion to the respiratory flow. The exhaled air was collected in a mixing chamber. $\mathrm{O}_{2}$ and $\mathrm{CO}_{2}$ sensors took samples of the exhaled air 


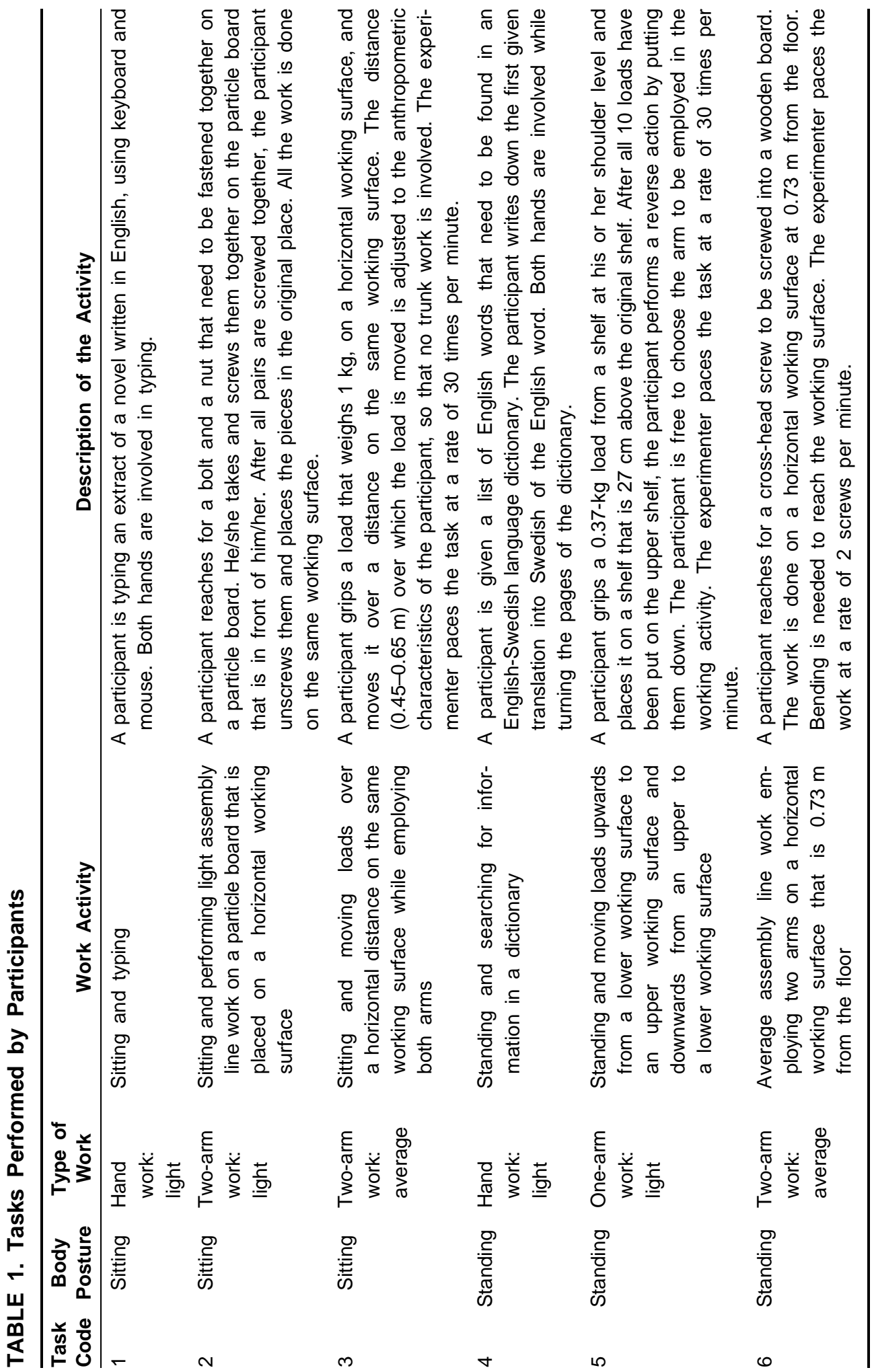


continuously and measured it twice a second. Parallel recordings of heart rate were made with a Polar ${ }^{\circledR}$ PE 3000 heart rate monitor (Polar Electro Oy, Finland) at $10 \mathrm{~s}$ intervals. Measured metabolic rate $\left(\mathrm{M}_{\text {Meas }}\right)$ was calculated from the $\mathrm{O}_{2}$ consumption using the partial method of measurement that is described in Standard No. ISO 8996 (ISO, 1990), which is recommended for the case of light and moderately heavy work.

After the participant's $M_{\text {Rest }}$ had been measured, the participant started to perform simulated work tasks. Each participant was assigned one random task after another until all six simulated tasks were performed. The preliminary period of 3-4 min for each new activity was followed by a main period of another 3-4 min of work. In addition, subjective estimates of exertion were obtained using the RPE scale (Borg, 1970). Before the experiment began, the participants were instructed how to rate the degree of exertion. They were asked to rate it as accurately and naively as possible. After a particular activity was completed the participant was immediately asked to mark a number on a scale according to how the work was experienced. The interpretation of $\mathrm{M}_{\text {Meas }}$ can be found in Standard No. ISO 8996 (ISO, 1990) and the Borg scale (RPE) is described in Borg's study (Borg, 1970).

\section{DATA ANALYSIS}

The significance of the results was evaluated with the Student's one-sample $t$ test (two-tailed). The differences were considered to be statistically significant when $p<.05$.

The average time-weighted oxygen consumption $\left(\mathrm{VO}_{2}\right)$ and respiratory quotient (RQ) were calculated for each of the participants from the values recorded during the last 3-4 min of a particular activity. Each participant's metabolic rate for a particular activity was calculated using the average time-weighted values of $\dot{\mathrm{VO}}_{2}$ and RQ. $\mathrm{M}_{\text {Meas }}$ for a particular activity was calculated as an average of each participant's values for that activity.

The mean heart rate for each activity was calculated from the heart rates recorded at $10 \mathrm{~s}$ intervals during the last 3-4 min of the activity performed by the participant. The index of cardiac strain: Net Cardiac Cost $(\mathrm{NCC})=$ Work heart rate - Rest heart rate (Chamoux, Borel, \& Catilina, 1985; Lablanche-Combier \& Ley, 1984) was used for the evaluation of work strain. The interpretation of NCC can be found in the study by Chamoux et al. (1985). 


\section{RESULTS}

Two of the participants had a slightly higher $\mathrm{M}_{\text {Rest }}$ (the average difference was 1 and $4 \mathrm{~W} / \mathrm{m}^{2}$ or 1.5 and $6.5 \%$ of $\mathrm{M}_{\text {Iso }}$ respectively) than $\mathrm{M}_{\mathrm{ISO}}$ for resting (Table 2). The Edholm scale does not have a category for $\mathrm{M}_{\text {Rest }}$, but for the category "Lying, sitting, break" the metabolic rate value is $55 \mathrm{~W} / \mathrm{m}^{2}$.

TABLE 2. Descriptive Statistics of MMeas Versus Miso and MEdh of Each Activity

\begin{tabular}{|c|c|c|c|c|c|c|}
\hline \multirow[b]{2}{*}{$\begin{array}{l}\text { Physiological } \\
\text { Measure }\end{array}$} & \multicolumn{4}{|c|}{ Descriptive Statistics } & \multirow[b]{2}{*}{$M_{\mathrm{Edh}}$} & \multirow[b]{2}{*}{$\mathbf{M}_{\text {Iso }}$} \\
\hline & $\begin{array}{c}\text { Mean/ } \\
\text { Median }\end{array}$ & $S D$ & Minimum & Maximum & & \\
\hline REST & & & & & & $\underline{65}$ \\
\hline$\overline{M_{\text {Meas }}}$ & 58.1 & 6.4 & 46.0 & 69.0 & & \\
\hline Heart rate $(\mathrm{HR})$ & 69.2 & 9.8 & 52 & 94 & & \\
\hline TASK 1 & & & & & $\underline{65}$ & 69 \\
\hline$\overline{M_{\text {Meas }}}$ & 64.5 & 8.0 & 50.4 & 80.8 & & \\
\hline Heart rate $(\mathrm{HR})$ & 74.5 & 8.3 & 63 & 101 & & \\
\hline Borg scale (RPE) & 8 & & 6 & 14 & & \\
\hline TASK 2 & & & & & 130 & 119 \\
\hline$\overline{M_{\text {Meas }}}$ & 79.6 & 10.0 & 60.0 & 98.3 & & \\
\hline Heart rate $(\mathrm{HR})$ & 77.7 & 8.6 & 66 & 104 & & \\
\hline Borg scale (RPE) & 11 & & 6 & 17 & & \\
\hline TASK 3 & & & & & 130 & 139 \\
\hline$\overline{M_{\text {Meas }}}$ & 86.2 & 13.5 & 61.9 & 110.1 & & \\
\hline Heart rate $(\mathrm{HR})$ & 81.6 & 8.5 & 68 & 100 & & \\
\hline Borg scale (RPE) & 12 & & 6 & 17 & & \\
\hline TASK 4 & & & & & 130 & 84 \\
\hline$\overline{\mathrm{M}_{\text {Meas }}}$ & 65.3 & 8.7 & 50.7 & 89.1 & & \\
\hline Heart rate $(\mathrm{HR})$ & 84.4 & 8.5 & 67 & 106 & & \\
\hline Borg scale (RPE) & 9 & & 6 & 15 & & \\
\hline TASK 5 & & & & & 130 & 104 \\
\hline$M_{\text {Meas }}$ & 84.1 & 11.8 & 65.1 & 113.6 & & \\
\hline Heart rate $(\mathrm{HR})$ & 86.1 & 10.1 & 52 & 107 & & \\
\hline Borg scale (RPE) & 11 & & 6 & 15 & & \\
\hline TASK 6 & & & & & $\underline{220}$ & 154 \\
\hline$M_{\text {Meas }}$ & 120.7 & 19.9 & 82.7 & 175.5 & & \\
\hline Heart rate $(\mathrm{HR})$ & 94.6 & 9.4 & 79 & 122 & & \\
\hline Borg scale (RPE) & 15 & & 7 & 19 & & \\
\hline
\end{tabular}

Notes. $\mathrm{M}_{\text {Meas }}$ - measured metabolic rate $\left(\mathrm{W} / \mathrm{m}^{2}\right), \mathrm{M}_{\mathrm{Edh}}$-metabolic rate derived from the Edholm scale $\left(\mathrm{W} / \mathrm{m}^{2}\right), \mathrm{M}_{\text {ISO }}$-metabolic rate derived from Standard No. ISO 8996 (ISO, 1990; W/m²), $\mathrm{M}_{\text {Rest }}$-morning resting metabolic rate $\left(\mathrm{W} / \mathrm{m}^{2}\right)$, HR-heart rate (beats/min). 

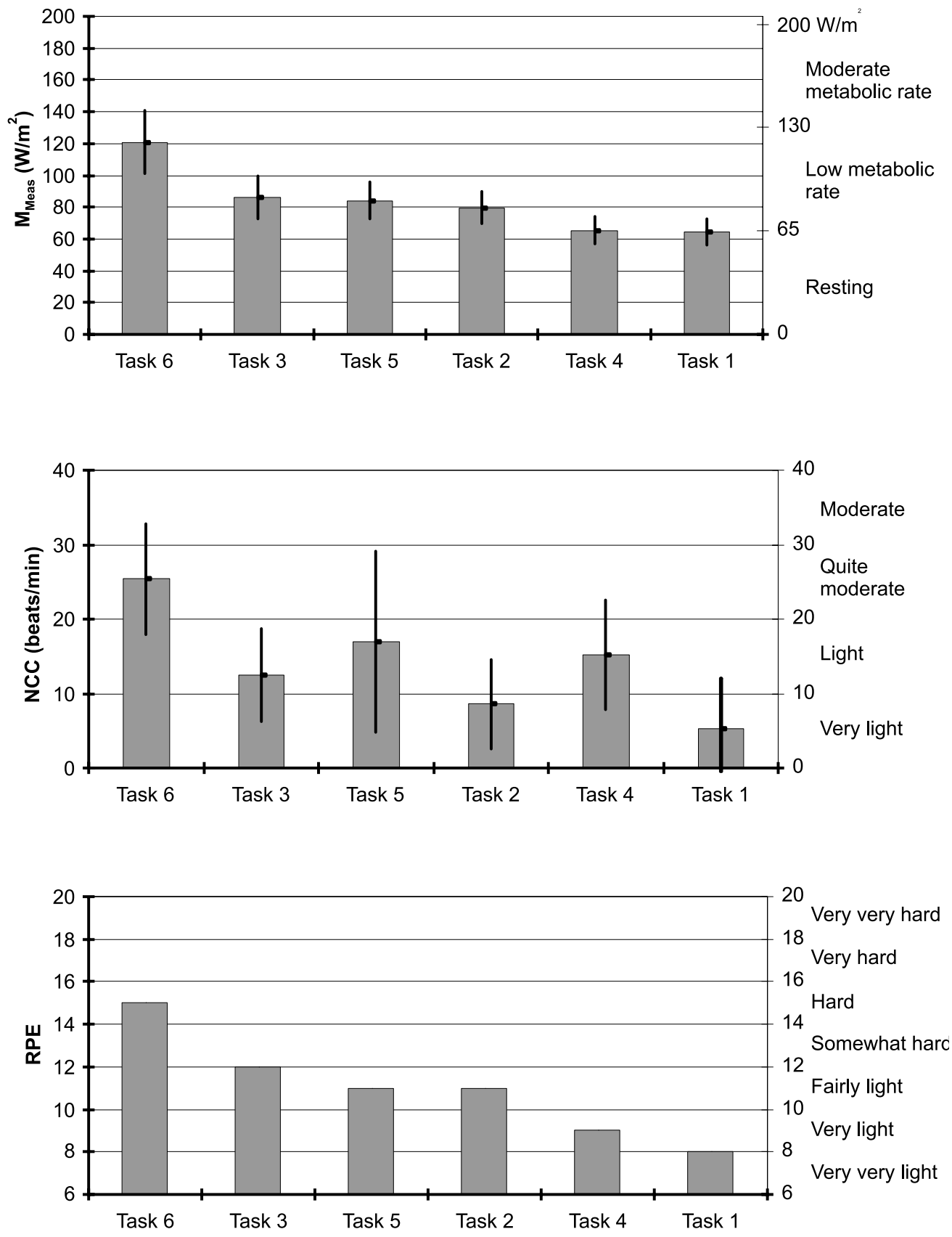

Figure 1. Evaluation of work strain according to $M_{\text {Meas }}\left(\mathrm{W} / \mathrm{m}^{2}\right), N C C$ (beats $/ \mathrm{min}$ ), and the Borg scale (RPE). The average values of $\mathrm{M}_{\text {Meas }}$ and NCC, and the median of RPE are given in thick bars. Thin bars denote standard deviation. Notes. $\mathrm{M}_{\text {Meas }}$-measured metabolic rate, NCC-Net Cardiac Cost, for description of tasks 1-6 see Table 1. 
In the conducted study $\mathrm{M}_{\mathrm{ISO}}$ overestimated $\mathrm{M}_{\text {Meas }}$ for all tasks by 7-38\% . Similarly to the comparison with Standard No. ISO 8996 (ISO, 1990), the Edholm scale overestimated $\mathrm{M}_{\text {Meas }}$ for all tasks except task $1 . \mathrm{M}_{\mathrm{Edh}}$ agreed with $\mathrm{M}_{\text {Meas }}$ solely for task 1 in this study, whereas $\mathrm{M}_{\text {Meas }}$ for the other five tasks were overestimated even more than by $\mathrm{M}_{\mathrm{ISO}}$, that is, by $34-50 \%$ of $\mathrm{M}_{\mathrm{Edh}}$.

Comparison of the $\mathrm{M}_{\mathrm{ISO}}$ values with each participant's $\mathrm{M}_{\text {Meas }}$, indicates both under- and overestimation. The $\mathrm{M}_{\text {Meas }}$ values from task 1 were lower than $\mathrm{M}_{\mathrm{ISO}}$ for 11 participants (the range of difference was $4-19 \mathrm{~W} / \mathrm{m}^{2}$ or $6-27 \%$ of $\mathrm{M}_{\mathrm{ISO}}$ ), higher for 7 other participants $\left(4-12 \mathrm{~W} / \mathrm{m}^{2}\right.$ or $6-17 \%$ of $\mathrm{M}_{\mathrm{ISO}}$ ) and one value equalled $\mathrm{M}_{\mathrm{ISO}}$. The $\mathrm{M}_{\text {Meas }}$ values were considerably lower than $\mathrm{M}_{\mathrm{ISO}}$ for all participants while performing task $2\left(21-59 \mathrm{~W} / \mathrm{m}^{2}\right.$ or $17-50 \%$ of $\left.\mathrm{M}_{\mathrm{ISO}}\right)$ and task $3\left(29-77 \mathrm{~W} / \mathrm{m}^{2}\right.$ or $21-55 \%$ of $\left.\mathrm{M}_{\mathrm{ISO}}\right)$. Tasks 4,5 , and 6 were performed at lower $\mathrm{M}_{\text {Meas }}$ than $\mathrm{M}_{\text {ISO }}$ by 18 participants. The differences between $\mathrm{M}_{\text {ISO }}$ and $\mathrm{M}_{\text {Meas }}$ were $11-30 \mathrm{~W} / \mathrm{m}^{2}$ or $13-37 \%, 2-39 \mathrm{~W} / \mathrm{m}^{2}$ or $2-37 \%$, and $10-67 \mathrm{~W} / \mathrm{m}^{2}$ or $7-44 \%$ for the respective tasks. $\mathrm{M}_{\text {Meas }}$ was higher than $\mathrm{M}_{\text {ISO }}$ for only 1 participant for task $4\left(10 \mathrm{~W} / \mathrm{m}^{2}\right.$ or $9 \%$ of $\left.\mathrm{M}_{\mathrm{ISO}}\right)$ and for another participant for task $5\left(10 \mathrm{~W} / \mathrm{m}^{2}\right.$ or $9 \%$ of $\left.\mathrm{M}_{\mathrm{ISO}}\right)$. Both of these participants had higher $\mathrm{M}_{\text {Meas }}$ than other participants had on average for the tasks performed. $\mathbf{M}_{\text {Meas }}$ equalled $\mathrm{M}_{\mathrm{ISO}}$ for one participant under task 6 .

The evaluation of work strain according to $\mathrm{M}_{\text {Meas }}\left(\mathrm{W} / \mathrm{m}^{2}\right)$, NCC (beats $\left./ \mathrm{min}\right)$, and the Borg scale (RPE) is given in Figure 1. All of the results from $\mathbf{M}_{\text {Meas }}$, NCC, and the Borg scale gave similar indications in the evaluation of strain of the participants. In fact, with reference to both $\mathrm{M}_{\text {Meas }}$ and NCC, the values obtained indicated that the work load was moderate-light for task 6 , whereas the other activities were indicated as light. The subjective evaluation of perceived exertion gave the same results: task 6 was rated as hard, whereas other tasks were indicated as fairly light to very light.

No differences in the work manner adopted by participants were observed in tasks 1, 3, 4, and 5. Differences were observed in the work posture (task 6) and the work technique (tasks 2 and 6) adopted by participants while performing the tasks.

\section{DISCUSSION}

The ISO standardisation helps to avoid similar scales with similar wording in the tabulated values corresponding to different values of metabolic rate, which usually causes problems in practical field work. 
Attempts have been made to modify the Edholm scale. Long and Louhevaara (1992) proposed a modified Edholm scale for manual handling jobs, based on the results of several studies on manual handling of postal parcels (Long \& Louhevaara, 1992; Louhevaara, Hakola, \& Ollila; 1990; Louhevaara, Teräslinna, Piirilä, Salmio, \& Ilmarinen, 1988).

The results of the present study are consistent with those reported by Ilmarinen et al. (1979) and Kähkönen et al. (1992). The study by Ilmarinen et al. (1979) showed that occupational activities in industries with no heavy physical work had been overestimated by the Edholm scale in the categories "Sitting or standing with very light movements or activities" and "Activities with low intensity," therefore they should be placed one category lower. The study of Kähkönen et al. (1992) reported that the metabolic rate derived from the Edholm scale was higher than that from the Standard No. ISO 7243 (ISO, 1989) tables.

The ISO standard sets an acceptability limit of $15 \%$ for relative errors calculated for the different indirect methods and $\pm 5 \%$ for measurements and time studies. Thus, if these acceptability limits are considered, only $\mathbf{M}_{\text {ISO }}$ for tasks 1 and 5 is the same as $\mathbf{M}_{\text {Meas }}$. However, even after considering the error limits $\mathbf{M}_{\mathrm{Edh}}$ does not become equal to $\mathbf{M}_{\text {Meas. }}$.

In addition, Standard No. ISO 8996 (ISO, 1990) states that the metabolic rate can vary from person to person by about $\pm 5 \%$ for the same work and under the same working conditions. According to the standard, metabolic rate values vary within certain limits because of the influence of work technique, work speed, and differences between work equipment. Those participating in the present study used different techniques in tasks 2 and 6, whereas in the other tasks no differences were observed. As these interindividual differences were observed even in very stereotyped tasks under laboratory conditions, it is concluded that the habits and the work procedures adopted by the participants are very important in determining energy expenditure under field conditions. All the participants used the same equipment during the entire experiment, thus the variation of $\mathbf{M}_{\text {Meas }}$ from participant to participant did not result from the use of different equipment. However, three of the tasks were not paced by the experimenter and this might have been a source of the differences in $\mathrm{M}_{\text {Meas }}$ values.

The energy cost of singular tasks in the Standard No. ISO 8996 (ISO, 1990) tables or the Edholm scale are given for a standard male person (1.7 m height, $70 \mathrm{~kg}$ weight, and a body surface of $1.8 \mathrm{~m}^{2}$ ), which can explain errors for participants differing from the standard. The anthropometric characteristics of the average person calculated for the participants of the 
present study are close to those indicated in the standard, although the range of values was rather wide: height $1.55-1.92 \mathrm{~m}$, weight $56-110 \mathrm{~kg}$, and body surface 1.59-2.26 $\mathrm{m}^{2}$. Additionally, the average participant in this study was younger (range of 21-38 years) than the reference person (35 years old) in Standard No. ISO 8996 (ISO, 1990). However, if the participants had been older an even a greater overestimation of $\mathbf{M}_{\text {Meas }}$ could be expected as the loss of fat-free mass (FFM) and reduction in basal metabolic rate (BMR) are believed to occur with ageing (Forbes, 1976; Tzankoff \& Norris, 1977).

Some of those participating in this study were engaged in sports like aerobics, running, or jogging on a daily basis, whereas others were practising some kind of sport occasionally. The authors did not ask the participants for details of their training program, so the effect of the training is not clear. However, studies conducted (Alméras, Mimeault, Serresse, Boulay, \& Tremblay, 1991; Meijer et al., 1991) suggested that the energy costs of daily physical activities were not different between trained and untrained participants. Furthermore, their experimental data also indicated that exercise training had a significant enhancing effect on resting metabolic rate.

The participants of the study represented three ethnic groups: Asians (4), Europeans (13), and Africans (2). There is some evidence suggesting that there are ethnic differences in the energy cost of standard activities. Energy expenditure for lying, sitting, and standing was reported to be lower in Africans and Asians living in Great Britain compared with Europeans, in participants matched by body dimensions (Geissler \& Aldouri, 1985). However, there were no significant differences in BMR, or in the energy cost of lying, sitting, and standing between Gurkha soldiers stationed in Great Britain and British controls matched by body weight and occupational background (Strickland \& Ulijaszek, 1990). Thus, it is left unknown if the fact that the participants were of three different races somehow influenced the results of the study.

The subjective evaluation of perceived exertion was more correlated to $\mathrm{M}_{\text {Meas }}$ than to NCC, which is in contrast to the consistency with the Borg scale. The same observation of HR inconsistency with the Borg scale was reported by Costa, Berti, and Betta (1989). It is plausible that the subjective evaluation of work strain does not refer only to the overall sensation of ]fatigue, but also to local strains, in particular on the musculoskeletal system due to bad postures or repetitive movements. For the same level of energy expenditure, it is known that HR is influenced by the mass of active muscles, the type of muscular contraction (dynamic or static), the thermal environment, and the physiological and psychological state of the participant (Horwat et al., 1988). HR may vary at each level of oxygen consumption, 
depending on which muscle groups are active (Åstrand \& Rodahl, 1977). It is well known that for a given $\mathrm{VO}_{2}$, heart rate is higher for static work than for dynamic work (Kilbom, 1976) and higher for work with small muscle groups than for work with large muscle mass (Stenberg, Åstrand, Ekblom, Royce, \& Saltin, 1967).

The Edholm scale expresses the metabolic cost of physical activity as a multiple of BMR. It is based on two assumptions: first, that the inter-individual variability in total energy expenditure for any group of participants is reflected in their BMR (Shetty \& Soares, 1988), and secondly, that BMR can, for reasons of simplicity, be predicted from body weight using linear equations specific for age and sex. The part of the Edholm scale dealing with BMR was not examined in this study. Thus for the full validation of the Edholm scale, studies correlating actual measured metabolic rates with those estimated as multiples of BMR should be conducted on different levels of work load.

\section{CONCLUSIONS}

$\mathrm{M}_{\mathrm{Edh}}$ overestimated the energy costs of five activities, and only the $\mathrm{M}_{\mathrm{Edh}}$ value of task 1 was the same (at significance level $\alpha=.05$ ) as $\mathrm{M}_{\text {Meas }}$. Even after considering the acceptability limit of $15 \%$ for the relative errors calculated for the different indirect methods, and $\pm 5 \%$ in measurements and time studies, the $M_{E d h}$ values were still higher than $M_{\text {Meas }}$. $M_{I S O}$ overestimated all of the activities, but if the accepted error limits are considered, the $\mathrm{M}_{\text {ISO }}$ values for tasks 1 and 5 were equal to those of $\mathrm{M}_{\text {Meas. }}$.

As the overestimation of the metabolic rate for the particular activities was sometimes up to $50 \%$ of $\mathrm{M}_{\mathrm{ISO}}$, it is recommended that the values of metabolic rate given in Standard No. ISO 8996 (ISO, 1990) for moderate and especially light activities should be reviewed. The same recommendation applies to the Edholm scale.

\section{REFERENCES}

Åstrand, P.O., \& Rodahl, K. (1977). Textbook of work physiology. New York, NY, USA: McGraw-Hill.

Alméras, N., Mimeault, N., Serresse, O., Boulay, M.R., \& Tremblay, A. (1991). Non-exercise daily energy expenditure and physical activity pattern in male endurance athletes. European Journal of Applied Physiology and Occupational Physiology, 63, 184-187. 
Bobet, J., \& Norman, R.W. (1982). Use of the average electromyogram in design evaluation. Investigation of a whole-body task. Ergonomics, 25(12), 1155-1163.

Borg, G. (1970). Perceived exertion as an indicator of somatic stress. Scandinavian Journal of Rehabilitation Medicine, 2(2), 92-98.

Chamoux, A., Borel, A.M., \& Catilina, P. (1985). Pour la standardisation d'une fréquence cardiaque de repos nocturne. Implications dans l'évaluation de la charge de travail [For the standardisation of the night resting heart-rate. Implications for the work load assessment]. Archives des Maladies Professionnelles de Médecine du Travail et de Sécurité Sociale, 46(4), 241-250.

Costa, G., Berti, F., \& Betta, A. (1989). Physiological cost of apple-farming activities. Applied Ergonomics, 20(4), 281-286.

Datta, S.R., \& Ramanathan, N.L. (1969). Energy expenditure in work predicted from heart rate and pulmonary ventilation. Journal of Applied Physiology, 26(3), 297-302.

Edholm, O.G. (1966). The assessment of habitual activity. In K. Evang \& K. Lange Andersen (Eds.), Physical activity in health and disease (pp. 187-197). Oslo, Norway: Universitets forlaget.

Fahlgren, M., Wiktorin, C., \& Bernmark, E. (1997). Energiomsättning vid sjukvårdsarbetejämförelse mellan beräknade och uppmätta värden [Energy expenditure during nursing activities - a comparison of estimated and actual measured values]. Nordisk Fysioterapi, 1, 135-141.

Forbes, G.M. (1976). The adult decline in lean body mass. Human Biology, 48(1), 161-173. Ford, A.B., \& Hellerstein, H.K. (1959). Estimation of energy expenditure from pulmonary ventilation. Journal of Applied Physiology, 14, 891-893.

Geissler, C.A., \& Aldouri, M.S.H. (1985). Racial differences in the energy cost of standardised activities. Annals of Nutrition and Metabolism, 29(1), 40-47.

Horwat, F., Meyer, J.P., \& Malchaire, J. (1988). Validation of a new pocket computer assisted method for metabolic rate estimation in field studies. Ergonomics, 31(8), 1155.

Ilmarinen, J., Knauth, P., Klimmer, F., \& Rutenfranz, J. (1979). The applicability of the Edholm scale for activity studies in industry. Ergonomics, 22(4), 369-376.

International Organization for Standardization (ISO). (1989). Hot environments-Estimation of the heat stress on working man, based on the WBGT-index. (Standard No. ISO 7243:1989). Geneva, Switzerland: Author.

International Organization for Standardization (ISO). (1990). Ergonomics-Determination of metabolic heat production (Standard No. ISO 8996:1990). Geneva, Switzerland: Author.

Kähkönen, E., Nykyri, E., Ilmarinen, R., Ketola, R., Lusa, S., Nygård, C.-H., \& Suurnäkki, T. (1992). The effect of appraisers in estimating metabolic rate with the Edholm scale. Applied Ergonomics, 23(3), 186-190.

Kilbom, A. (1976). Circulatory adaptation during static muscular contractions. Scandinavian Journal of Work, Environment and Health, 2, 1-13.

Lablanche-Combier, B., \& Ley, F. (1984). Utilisation de l'enregistrement electrocardiographique dans l'évaluation de la charge de travail des chantiers miniers chaud [The use of ambulatory electrocardiographic monitoring in the evaluation of the work load in hot mining]. Archives des Maladies Professionnelles de Médecine du Travail et de Sécurité Sociale, 5, 323-332.

Long, A.F., \& Louhevaara, V. (1992). Computerised collection and analysis of minute by minute physical activity and work phase data. In M. Mattila \& W. Karwowski (Eds.), 
Computer applications in ergonomics, occupational safety and health (pp. 445-451). Amsterdam, The Netherlands: Elsevier Science.

Louhevaara, V., Hakola, T., \& Ollila, H. (1990). Physical work and strain involved in manual sorting of postal parcels. Ergonomics, 33(9), 1115-1130.

Louhevaara, V., Teräslinna, P., Piirilä, P., Salmio, S., \& Ilmarinen, J. (1988). Physiological responses during and after intermittent sorting of postal parcels. Ergonomics, 31(8), 1165-1175.

Malchaire, J., Wallemacq, M., Rogowsky, M., \& Vanderputten, M. (1984). Validity of oxygen consumption. Measurement at the workplace. What are we measuring? Annals of Occupational Hygiene, 28(2), 189-193.

Meijer, G.A.L., Janssen, G.M.E., Westerterp, K.R., Verhoeven, F., Saris, W.H.M., \& ten Hoor, F. (1991). The effect of a 5-month endurance-training programme on physical activity: Evidence for a sex-difference in the metabolic response to exercise. European Journal of Applied Physiology and Occupational Physiology, 62(1), 11-17.

Montoye, H.J., Washburn, R., Servais, S., Ertl, A., Webster, J.G., \& Nagle, F.J. (1983). Estimation of energy expenditure by a portable accelerometer. Medicine and Science in Sports and Exercise, 15(5), 403-407.

Muzi, M., Ebert, T.J., Tristani, F.E., Jeutter, D.C., Barney, J.A., \& Smith, J.J. (1985). Determination of cardiac output using ensemble averaged impedance cardiograms. Journal of Applied Physiology, 58(1), 200-205.

Nielsen, R., \& Meyer, J.P. (1987). Evaluation of metabolism from heart rate in industrial work. Ergonomics, 30(3), 563-572.

Shetty, P.S., \& Soares, M.J. (1988). Variability in basal metabolic rates of man. In K. Blaxter \& I. MacDonald (Eds.), Comparative nutrition (pp. 141-148). London, UK: John Libbey.

Stenberg, J., Åstrand, P.O., Ekblom, B., Royce, J., \& Saltin, B. (1967). Hemodynamic response to work with different muscle groups, sitting and supine. Journal of Applied Physiology, 22(1), 61-70.

Strickland, S.S., \& Ulijaszek, S.J. (1990). Energetic cost of standard activities in Gurkha and British soldiers. Annals of Human Biology, 17(2), 133-144.

Tzankoff, S.P., \& Norris, A.H. (1977). Effect of muscle mass decrease on age related BMR changes. Journal of Applied Physiology and Respiratory and Environmental Exercise Physiology, 43(6), 1001-1006. 